\title{
SINONASAL MASS - A DIVERSE CLINICOPATHOLOGICAL ENTITY - AN EXPERIENCE IN A TERTIARY CARE CENTRE IN THE NORTH EASTERN INDIA
}

\author{
Soumyajit Das ${ }^{1}$, Debajit Das ${ }^{2}$ \\ ${ }^{1}$ Assistant Professor, Department of ENT, Sikkim Manipal Institute of Medical Sciences, Gangtok, Sikkim. \\ 2Professor and HOD, Department of ENT, Assam Medical College and Hospital, Dibrugarh, Assam.
}

\section{ABSTRACT}

\section{BACKGROUND}

Mass in the nasal cavity is frequently encountered in routine ENT practice. The histopathological profiles of these masses are diverse and diagnosis can often be challenging for the clinician and the pathologist.

\section{MATERIALS AND METHODS}

A one-year observational study was conducted in a tertiary care centre to study the clinicopathological profile of sinonasal mass.

\section{RESULTS}

A total of 34 cases were included in the study which included 22 males and 12 females. The most common presenting complaints were nasal obstruction (88.2\%) followed by epistaxis (44.1\%). Though majority of the patients presented within six months of onset of symptoms, about $35.3 \%$ of the patients presented within six to twelve months of the onset of symptoms. Sinonasal polyps (47.1\%) were the most common histological diagnosis while squamous cell carcinoma of the maxilla was the most common malignancy (17.6\%), followed by sinonasal lymphoma and melanoma (5.9\% each) and olfactory neuroblastoma (2.9\%). $73 \%$ of the lesions were amenable to surgical treatment.

\section{CONCLUSION}

The treatment of sinonasal lesions depend on the histological profile and the diagnosis of the same can often be a challenging task. One has to be aware of the differential diagnosis and rule them out by proper histological evaluation.

\section{KEYWORDS}

Sinonasal Polyposis, Nasal Mass, Maxillary Carcinoma, Lymphoma, Olfactory Neuroblastoma, Haemangioma.

HOW TO CITE THIS ARTICLE: Das S, Das D.Sinonasal mass - A diverse clinicopathological entity - An experience in a tertiary care centre in the north-eastern India. J. Evolution Med. Dent. Sci. 2016;5(89):6651-6656, DOI: 10.14260/Jemds/2016/1504

\section{BACKGROUND}

The presence of mass in the nose and paranasal sinus is a very common finding in day-to-day ENT clinic visits. These may be inflammatory including allergic, traumatic or granulomatous lesions or malignancies. As such its wide spectrum raises various questions about the differential diagnosis. Nasal polyps as a part of sinonasal mass have been recognised since the time of ancient Egyptians and their removal with snares was described by Hippocrates. Undoubtedly, nasal polyps constitute the most common nasal masses. Overall malignant sinonasal tumours comprise less than $1 \%$ of all malignant tumours and less than $3 \%$ of upper aerodigestive tract malignancies. ${ }^{1}$ Due to its close proximity to orbits and the skull base, sinonasal tumours have great propensity to invade these structures and as such prognosis remains grim for advanced lesions. Sinonasal malignancies most commonly affect the nasal cavity (44\%), followed by maxillary sinus (about 36\%), ethmoid sinus (9.5\%), frontal sinus (1.1\%) and sphenoid sinus (3.3\%). ${ }^{1}$ Sinonasal tract tumours are diverse histologically

Financial or Other, Competing Interest: None.

Submission 03-10-2016, Peer Review 27-10-2016,

Acceptance 02-11-2016, Published 07-11-2016.

Corresponding Author:

Dr. Soumyajit Das,

Assistant Professor

Department of ENT,

Sikkim Manipal Institute of Medical Sciences,

$5^{\text {th }}$ Mile, Tadong, Gangtok-737102,

Sikkim, India.

E-mail:drsoumya_entamch@rediffmail.com

DOI: $10.14260 /$ jemds/2016/1504 with majority being SCC and variants (51.6\%). Other histological entity include adenocarcinoma, melanoma, esthesioneuroblastoma and sinonasal undifferentiated carcinoma (SNUC).

Sinonasal mass, is one of the most fascinating clinical entity because of its diverse histological group and its elusive early symptoms which more often than not mimic chronic sinusitis. The objective was to study the clinicopathological profile of sinonasal tumours/lesions encountered over a period of one year and to assess the various diagnostic difficulties faced with some uncommon tumours.

\section{MATERIALS AND METHODS}

All patients of all age group with nasal or paranasal sinus mass or destructive sinonasal lesions irrespective of histological outcome were included in the study. Nasopharyngeal carcinoma has been excluded from the study group. All patients presenting to ENT outpatient department (OPD) and emergency services from January 2010 to December 2010 with nasal mass or destructive lesion of nasal and paranasal sinus were included in the study after detailed history and thorough clinical examination. The lesions were subjected to a diagnostic nasal endoscopy and radiological evaluation was done with a computed tomography (CT) scan and or magnetic resonance imaging (MRI) wherever indicated. The final diagnosis was confirmed by histology. The patients were followed up for a minimum period of one year after the treatment. The study was an observational study, and patients were included into the study after obtaining written consent and necessary ethical clearance. 


\section{RESULTS AND OBSERVATIONS}

A total 34 cases were recorded during the study period of which $64.7 \%$ (22 cases) were males and $35.3 \%$ (12 cases) were females. Majority of the patients belonged to the age group of $20-40$ years (32.3\%) [Table 1]. 23 cases $(67.6 \%)$ were benign in nature while 11 cases $(32.3 \%)$ were malignant. The presenting symptoms and clinical findings are shown in Table 2 and Table 3 respectively. Most of the patients presented within six months of presentation of symptoms [Figure 1]. The most common histological diagnosis was sinonasal polyps (47.1\%). The breakup of the histological diagnosis of the lesions are shown in Table 4. It is important to note that certain conditions presenting as a sinonasal mass pose significant diagnostic challenge. These include melanoma of the nose and paranasal sinus, olfactory neuroblastoma (OLN) and sinonasal lymphoma. In this series, OLN and one case of amelanotic melanoma were clinically diagnosed as polyps. Radiological feature of the melanoma was indistinguishable from a polyp and was diagnosed at biopsy after immunohistochemistry (IHC). The case of OLN was suspected due to its radiological features which showed involvement of the olfactory fossa and the cribriform plate and was confirmed with a prior biopsy. All the patients diagnosed with squamous cell carcinoma of maxilla (six cases) presented at an advanced stage and refused surgery and were subsequently treated with radiotherapy. Of these, two patients had residual tumour and refused further treatment, one died of the disease and the rest were lost to followup. Two cases of sinonasal lymphoma were diagnosed where one had intracranial metastasis and died of the disease. The other case of lymphoma was diagnosed by IHC as extranodal NK/T cell lymphoma nasal type and needed multiple biopsies from different areas of the granulation filled nasal cavity. The patient was a young male and responded favourably to chemoradiation and remained disease free for one year after the treatment and was subsequently lost to followup. The details of the followup of the patients are shown in Table 5.

\begin{tabular}{|c|c|c|}
\hline Age (Yrs.) & No. of Patients & Percentage \\
\hline$<20$ & 7 & $20.6 \%$ \\
\hline $20-40$ & 11 & $32.3 \%$ \\
\hline $41-60$ & 10 & $29.4 \%$ \\
\hline $61-80$ & 5 & $14.7 \%$ \\
\hline$>80$ & 1 & $3 \%$ \\
\hline TOTAL & 34 & $100 \%$ \\
\hline \multicolumn{2}{|c|}{ Table 1. Table showing Age Distribution of the Patients }
\end{tabular}

\begin{tabular}{|c|c|c|}
\hline Symptoms & $\begin{array}{c}\text { No. of } \\
\text { Cases }\end{array}$ & Percentage \\
\hline Nasal obstruction & 30 & $88.2 \%$ \\
\hline Epistaxis & 15 & $44.1 \%$ \\
\hline $\begin{array}{c}\text { Mass protruding from nasal } \\
\text { cavity }\end{array}$ & 8 & $23.5 \%$ \\
\hline Pain & 7 & $20.6 \%$ \\
\hline Cheek mass & 7 & $20.6 \%$ \\
\hline Repeated sneezing & 6 & $17.6 \%$ \\
\hline Discharge & 16 & $47.1 \%$ \\
\hline Anosmia & 4 & $11.8 \%$ \\
\hline Proptosis & 3 & $8.9 \%$ \\
\hline Visual loss & 2 & $5.9 \%$ \\
\hline Loose tooth & 2 & $5.9 \%$ \\
\hline Table 2. Table showing Common Presenting Symptoms \\
\hline
\end{tabular}

\begin{tabular}{|c|c|c|}
\hline Clinical Findings & $\begin{array}{c}\text { Total No. of } \\
\text { Patients }\end{array}$ & Percentage \\
\hline Mass in nasal cavity & 28 & $82.3 \%$ \\
\hline Facial swelling & 7 & $20.6 \%$ \\
\hline Mass in nasopharynx & 6 & $17.6 \%$ \\
\hline $\begin{array}{c}\text { Palatal and gum } \\
\text { involvement }\end{array}$ & 6 & $17.6 \%$ \\
\hline Orbital extension & 3 & $8.9 \%$ \\
\hline $\begin{array}{c}\text { Granulations in nasal } \\
\text { cavity with crusting }\end{array}$ & 2 & $5.9 \%$ \\
\hline $\begin{array}{c}\text { Palpable Cervical } \\
\text { lymphadenopathy }\end{array}$ & 2 & $5.9 \%$ \\
\hline Cranial nerve palsy & 1 & $2.9 \%$ \\
\hline Features of raised ICT & 1 & $2.9 \%$ \\
\hline \multicolumn{2}{|c|}{ Table 3. Table showing Clinical Findings } \\
\hline
\end{tabular}

\begin{tabular}{|c|c|c|c|c|}
\hline $\begin{array}{l}\text { Types of } \\
\text { Lesion }\end{array}$ & $\begin{array}{c}\text { No. } \\
\text { of } \\
\text { Cases }\end{array}$ & Percentage & Male & Female \\
\hline Polyp & 16 & $47.1 \%$ & 10 & 6 \\
\hline $\begin{array}{l}\text { Sq cell Ca } \\
\text { Maxilla }\end{array}$ & 6 & $17.6 \%$ & 4 & 2 \\
\hline $\begin{array}{l}\text { Nasopharyngeal } \\
\text { angiofibroma }\end{array}$ & 3 & $8.9 \%$ & 3 & 0 \\
\hline Melanoma & 2 & $5.9 \%$ & 1 & 1 \\
\hline $\begin{array}{c}\text { Sinonasal } \\
\text { Lymphoma }\end{array}$ & 2 & $5.9 \%$ & 2 & 0 \\
\hline Haemangioma & 2 & $5.9 \%$ & 0 & 2 \\
\hline $\begin{array}{l}\text { Inverted } \\
\text { papilloma }\end{array}$ & 2 & $5.9 \%$ & 2 & 0 \\
\hline OLN & 1 & $2.9 \%$ & 0 & 1 \\
\hline Total & 34 & $100 \%$ & 22 & 12 \\
\hline \multicolumn{5}{|c|}{$\begin{array}{c}\text { Table 4. Table showing Final Diagnosis on the basis of } \\
\text { Histopathology Report and their Distribution on the } \\
\text { Basis of Sex }\end{array}$} \\
\hline
\end{tabular}

\begin{tabular}{|c|c|c|c|c|c|c|c|}
\hline 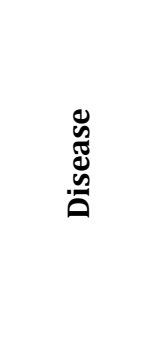 & 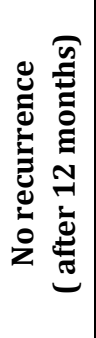 & 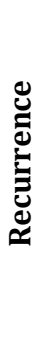 & 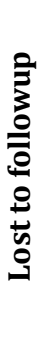 & 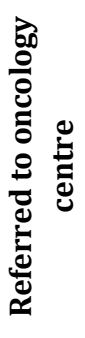 & 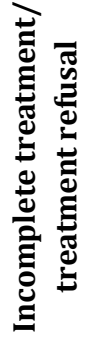 & 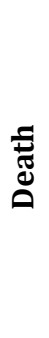 & 竎 \\
\hline Melanoma & 2 & 0 & 0 & 0 & 0 & 0 & 2 \\
\hline Ca Maxilla & 0 & 2 & 1 & 0 & 2 & 1 & 6 \\
\hline $\begin{array}{l}\text { Inverted } \\
\text { papilloma }\end{array}$ & 2 & 0 & 0 & 0 & 0 & 0 & 2 \\
\hline Lymphoma & 1 & 0 & 0 & 0 & 0 & 1 & 2 \\
\hline OLN & 0 & 0 & 0 & 1 & 0 & 0 & 1 \\
\hline Polyp & 9 & 3 & 4 & 0 & 0 & 0 & 16 \\
\hline $\begin{array}{c}\text { Haemangio } \\
\text { ma }\end{array}$ & 2 & 0 & 0 & 0 & 0 & 0 & 2 \\
\hline JNA & 3 & 0 & 0 & 0 & 0 & 0 & 3 \\
\hline
\end{tabular}




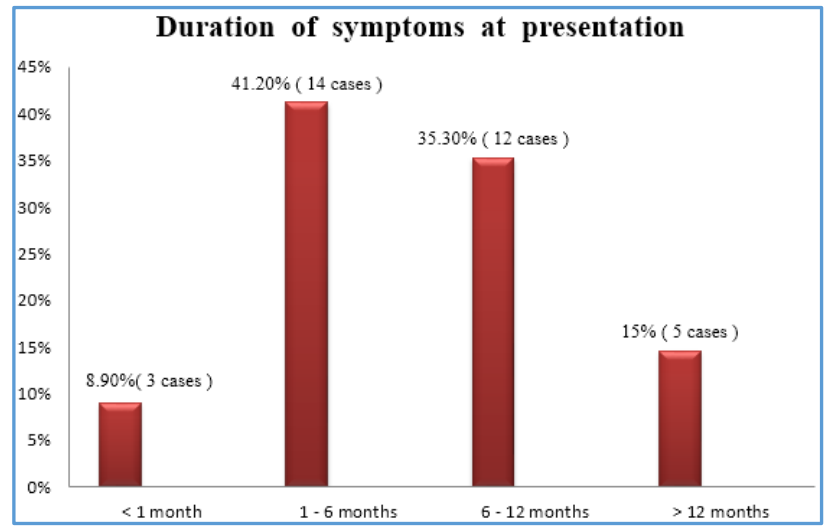

Chart 1. Chart showing Duration of Symptoms at Presentation

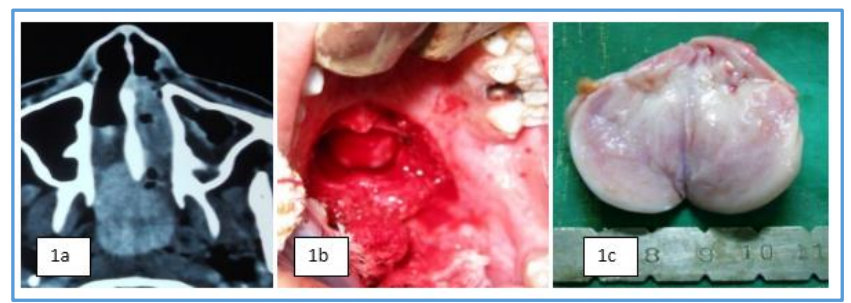

Figure 1a. CT Scan showing a Contrast Enhanced Mass in the Nasal Cavity and Nasopharynx.

1b: Nasopharyngeal Angiofibroma Exposed by the Transpalatal Approach.

1c: Excised Specimen of Angiofibroma Cut open

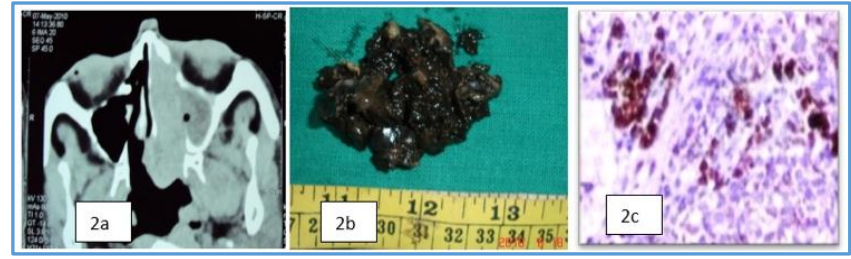

Figure 2a. CT Scan of a Patient presenting with Polypoidal Nasal Mass eventually Diagnosed as Melanoma. 2b: Excised Specimen of a Case of Nasal Melanoma. 2c: Immunohistochemical Staining for HMB-45 Protein showing Strong Positivity in Melanoma Cells (×400)

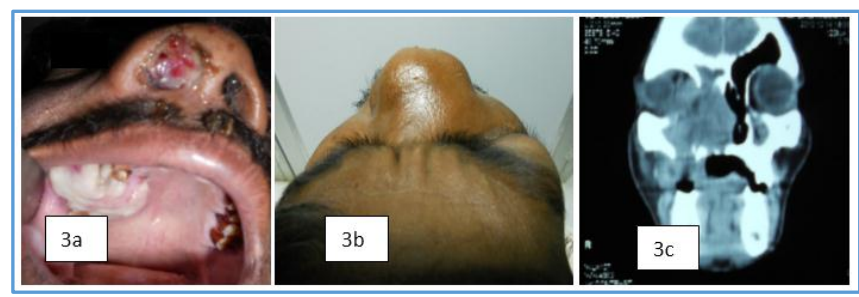

Figure 3a. Clinical Presentation of a Case of Squamous Cell Carcinoma of the Right Maxilla.

3b: Photograph of the Same Patient showing Proptosis Right Side with Cheek Involvement

3c: A Coronal Cut CT Scan of the same Patient showing Widespread Bone Destruction

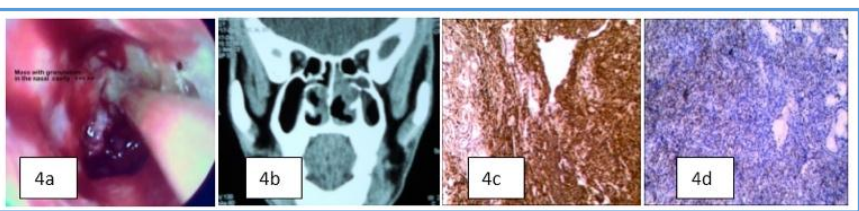

Figure 4a. Endoscopic Picture of a Patient Presenting with

Mass and Granulation Tissue in the Nasal Cavity.

$4 b$ A Coronal Section of CT scan of the Same Patient.

4c \& 4d Immunohistochemical Staining showing Positivity with CD 3 and CD 56 Respectively (10X).

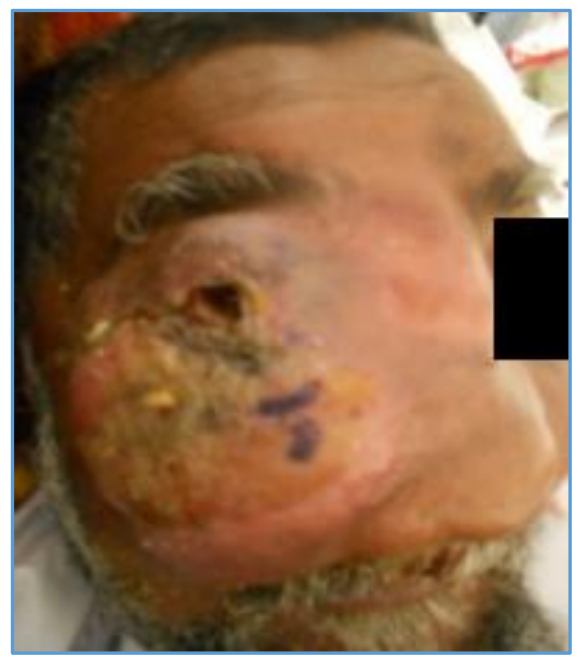

Figure 5. Patient of Sinonasal Lymphoma presenting with Nasal Mass with Extranasal and Intracranial Extension

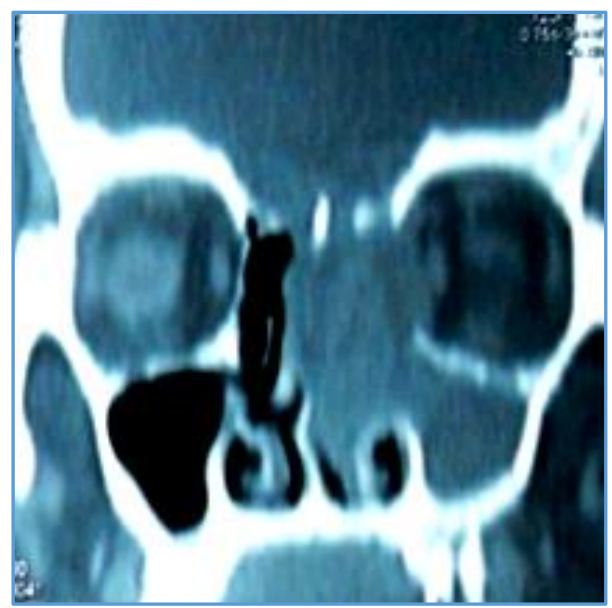

Figure 6. Coronal Cut CT Scan of a Patient Presenting with Polypoidal Mass in the Nasal Cavity showing Involvement of the Cribriform Area. The Mass was Subsequently Diagnosed as an Olfactory Neuroblastoma

\section{DISCUSSION}

The study included 34 patients. Of them, 64.7\% (22 cases) were males and the rest were females. Bakhari et al found a slight female preponderance in their study (M:F=1:1.2) ${ }^{2}$ while a study carried out among the Indian population found a higher ratio of males.3,4,5 It is thus seen that sinonasal mass has a predilection to occur more commonly among the male population. The reason for this is not known and could be due to the relatively more exposure of the male population to environmental allergens or carcinogens. Most of the patients 
(32.3\%, 11 patients) in this study belonged to the age group of $20-40$ yrs. In the study by Lathi et al, almost $40 \%$ of the patients belonged to the age group 21-40 yrs. ${ }^{3}$

Nasal obstruction remains the most common presenting symptom (88.2\% in the present series) and correlates with the clinical finding of mass in the nasal cavity $(82.3 \%$ in present study). Early malignancy presents with nonspecific symptoms which often result in a delay in diagnosis. Presence of epistaxis, should indicate towards a possibility of a vascular lesion, granulomatous or acute inflammation or malignancy. Proptosis as a presenting symptom is found in only 20\% benign sinonasal conditions while it is encountered in almost $80 \%$ of cases of sinonasal malignancies. ${ }^{6}$ In a study of 112 cases by Bist et al, eye involvement was found in only $10 \%$ of the total cases of sinonasal mass. ${ }^{7}$ In the present study, ocular involvement in the form of proptosis was seen in 3 cases $(8.9 \%)$ all of which were malignancies. Evidence of bone erosion or infiltration and invasion to nearby structures should alert the clinician of the possibility of malignancy or granulomatous lesion.

When these patients were evaluated the most common clinical finding was a mass in the nasal cavity (28 patients, $82.3 \%)$. In 6 cases (17.6\%), there was extension of the mass into the nasopharynx and in 2 cases (5.9\%) there was ill defined mass with granulation in the nasal cavity. Facial swelling was present in 7 cases (20.6\%) and palatal and gum involvement was found in all 6 cases $(17.6 \%)$ of Ca maxilla. 5 cases $(14.7 \%)$ had orbital extension. Cervical lymphadenopathy was present in only two cases (5.9\%) of Ca maxilla and compressive optic neuropathy was present in the case of olfactory neuroblastoma. Bist et al found nasal mass in approximately $48.2 \%$ cases and facial swelling in $27.2 \%$ of the patients and cervical lymphadenopathy in $9.1 \%$ of the patients. ${ }^{7}$ One patient of sinonasal lymphoma had intracranial extension and was found to have features of raised intracranial tension on clinical examination.

It is interesting to study the time of first consultation with an otorhinolaryngologist since the onset of initial symptoms. Most cases presented within a span of 1-6 months of onset of symptoms (14 patients, 41.2\%). However, a significant proportion (12 patients, $35.3 \%$ ) of cases presented at least 612 months after onset of symptoms. All six cases of carcinoma maxilla who presented to us had symptoms ranging from 7-8 months and presented with advanced lesions. Those who presented within 1 month had severe nasal bleed as their main complaints which forced them to seek medical attention early. 5 patients (14.6\%) presented after 12 months of onset of symptoms. Of this group, one was a case of sinonasal lymphoma with intracranial extension and the rest were nasal polyps. These findings suggest a relative lack of awareness of sinonasal malignancy and its symptoms among the patients.

Many a time, the symptoms of early sinonasal malignancy are treated as nonspecific rhinitis without proper evaluation. In a study in West Nigeria, almost $47 \%$ of the patients were found to present at least a year after onset of symptoms and the factors contributing to such delay included selfmedication, practice of herbal medications and inappropriate advice. ${ }^{8} \mathrm{~A}$ study conducted in Northern India found only $25 \%$ patients who presented within 3 months of onset of symptoms. ${ }^{7}$ The figures in the rural population and among the underprivileged can only be assumed as the exact data are lacking.
Sinonasal lesions are diverse in their histological profile and often provide a diagnostic and therapeutic challenge. Majority of the lesions are benign in nature as seen in the present study (23 cases, 67.6\%). Sinonasal polyps comprised the most common lesions $(47.1 \%)$ followed by angiofibroma (8.9\%), haemangioma (5.9\%) and inverted papilloma (5.9\%). Almost similar findings were noted by Kalpana et al $^{4}$ while Lathi et al found a higher percentage $(71.4 \%)$ in their study. ${ }^{3}$

Benign polyps are the most common non-neoplastic lesions as seen in various studies. $2,3,4,5,7,9$ Polyps remain a simple clinical diagnosis, but it should always be confirmed histologically. Rarely polyps may masquerade an underlying malignancy. Amelanotic melanoma may also be mistaken as a polyp if one is unaware of the entity.10,11

Juvenile nasopharyngeal angiofibroma comprised almost $5-6 \%$ of sinonasal tumours in studies among Indian population ${ }^{3,4}$ and its overall incidence has been quoted to be 0.05 to $0.5 \%$ of all head and neck neoplasms. ${ }^{12}$ It is worth mentioning that these tumours are highly vascular tumours which can be diagnosed on the basis of its typical history, clinical examination and radiological and angiographic findings. ${ }^{13}$ Preoperative biopsy is contraindicated because of the risk of torrential bleeding. Nasal haemangiomas are rare lesions and are mostly capillary type and arise from the nasal septum. Cavernous haemangioma usually arise from the lateral nasal wall and have similar presentation like that of the capillary counterpart. ${ }^{14}$ It is important to differentiate these lesions from those arising from the nasal bones or the maxilla which are primarily bony lesions and warrant a different surgical approach. 15

Inverted papilloma constitutes $0.4 \%$ to $4 \%$ of all sinonasal tumours ${ }^{16,17}$ and in studies on Indian population inverted papilloma comprised nearly $6 \%$ of all sinonasal tumours.3,4 Though rarely these tumours may be bilateral, inverted papilloma tumours should always be suspected in case of unilateral nasal mass in patients above 40 years age. Although not seen in the present study, it is not unusual to encounter fibro-osseous lesions, schwannoma, dentigerous cyst and rarely microcystic papillary adenoma and spindle cell lesions which may present with a mass in the nasal cavity. ${ }^{7,4}$

Squamous cell carcinoma (SCC) of the maxillary sinus was the most common malignant lesion encountered (17.6\%) followed by 2 cases $(5.9 \%)$ of melanoma and sinonasal lymphoma each and one case of olfactory neuroblastoma $(2.9 \%)$. SCC maxilla is the commonest sinonasal malignancy. $3,7,9,18$ SCC of paranasal sinus is a straightforward histological diagnosis provided the tissue sampling is done from the representative areas. Certain conditions like sinonasal lymphoma, olfactory neuroblastoma and melanoma can challenge the pathologist and cause delayed diagnosis. In the present study, there were two cases (5.9\%) of sinonasal lymphoma and one case of melanoma and olfactory neuroblastoma each.

Sinonasal lymphomas are rare tumours but have aggressive course and require immunohistological typing to arrive at a definitive diagnosis. ${ }^{19}$ One of the patients in the study was diagnosed as extranodal NK/T cell lymphoma nasal type while in the other patient definitive typing of lymphoma could not be done. Extranodal NK/T cell lymphoma can occur in any age group with peak incidence in $5^{\text {th }}$ decade and are more frequent among the Asian population. These tumours are found to be associated with Epstein Barr virus and the 
prodromal stage of the disease may have an indolent course that may last many years. ${ }^{19,20,21}$ These tumours show positive immunostaining to CD3, CD56. ${ }^{21,22}$

Olfactory neuroblastoma is a rare tumour. Tural et al found only nineteen cases in a 24-year retrospective analysis. ${ }^{23} \mathrm{~A}$ retrospective study by Menon et al conducted in one of the premier tertiary care oncology referral centre in India found about 14 cases of olfactory neuroblastoma over a period of 5 years study. ${ }^{24}$ Preoperative diagnosis helps in proper planning and management of these tumours as they frequently involve the cribriform area and require a craniofacial resection for complete tumour removal. The patient in the present study was diagnosed preoperatively and had radiological evidence of involvement of the cribriform area and was referred to an oncology centre for further treatment.

Most of the lesions in the present study were treated surgically ( 25 cases, $73.5 \%$ ). Of them, 18 cases (which included 16 polyps $\& 2$ haemangiomas) were addressed by endoscopic approach, 3 cases of angiofibroma were dealt by transpalatal approach while 4 cases ( 2 cases of inverted papilloma and 2 nasal melanomas) required lateral rhinotomy approach for complete tumour removal. Surgery is the mainstay of treatment for most lesions and in the present day scenario, ESS remains the gold standard for many sinonasal tumours. Even highly vascular lesions like angiofibroma can be removed endoscopically. ${ }^{13}$ In the present study, all the cases of JNA were addressed by the transpalatal approach with complete resection and without recurrence. Various other approaches like lateral rhinotomy, Caldwell-Luc approach, etc. may be undertaken depending on the pathology and the extent of the lesion.

We encountered a recurrence of $25 \%$ among the 12 postoperative cases of nasal polyps in patients who were under regular followup for at least one year (4 patients lost to followup). The recurrence rates of sinonasal polyposis are high and has been found to be $19 \%$ and $60 \%$ in studies by Akhtar et al and Wynn et al respectively. ${ }^{25,26}$ Inverted papilloma has a tendency of recurrence and proper surgical planning is recommended to minimise such recurrence. Saha et al found a recurrence rate of $38 \%$ of cases. ${ }^{27}$ Barnes quotes a recurrence rate of $0-30 \%$ within $2-3$ years following lateral rhinotomy and medial maxillectomy. ${ }^{28} \mathrm{Few}$ cases were lost to followup and as such the final outcome of all the cases in the study are not known. Effective surgical resection of maxillary carcinoma followed by postoperative chemoradiation is associated with better outcome. ${ }^{3}$ However, even with multimodality treatment, the overall prognosis is disappointing. ${ }^{29}$ Sinonasal lymphoma responds to chemoradiation. Even though early diagnosis is associated with a better diagnosis, 30 the 5 -year survival rate is about $50 \% .31$

\section{CONCLUSION}

Sinonasal masses are encountered commonly but are of diverse histological profile. The management and prognosis of the lesions also vary depending on the histology. A clinician and the pathologist should be aware of all the possible differential diagnosis of a mass in the nasal cavity and rule them out. We suggest that every tissue removed from the nasal cavity be subjected for histopathological evaluation so as not to miss out on any uncommon lesions. It is also important to make the general population aware of symptoms of sinonasal pathology and encourage them to seek early consultation. As has been seen, there is chance of recurrence in certain histological entity, so regular followup is needed. It is also necessary to initiate a multicentric study to know the clinical behaviour and the response rates of certain uncommon lesions of the nose and paranasal sinus so that a uniform treatment protocol can be formulated.

\section{REFERENCES}

1. Turner JH, Reh DD. Incidence and survival in patients with sinonasal cancer: a historical analysis of population-based data. Head Neck 2012;34(6):877-85.

2. Bakari A, Afolabi OA, Adoga AA, et al. Clinico-pathological profile of sinonasal masses: An experience in national ear care center, Kaduna, Nigeria. BMC Research Notes 2010;3:186.

3. Lathi A, Syed MM, Kalakoti P, et al. Clinico-pathological profile of sinonasal masses: a study from a tertiary care hospital of India. Acta Otorhinolaryngologica Italica 2011;31(6):372-7.

4. Kumari KMK, Mahadeva KC. Polypoidal lesions in the nasal cavity. Journal of Clinical and Diagnostic Research 2013;7(6):1040-42.

5. Zafar U, Khan N, Afroz N, et al. Clinicopathological study of non-neoplastic lesions of nasal cavity and paranasal sinuses. Indian J Pathol Microbiol 2008;51(1):26-9.

6. Keche P, Nitnaware AZ, Mair M, et al. A study of tumours giving rise to unilateral proptosis. Indian J Otolaryngol Head Neck Surg 2013;65(Suppl 1):S6-S13.

7. Bist SS, Varshney S, Baunthiyal V, et al. Clinico-pathological profile of sinonasal masses: an experi ence in tertiary care hospital of Uttarakhand. Natl J Maxillofac Surg 2012;3(2):180-6.

8. Fasunla AJ, Ogunkeyede SA. Factors contributing to poor management outcome of sinonasal malignancies in southwest Nigeria. Ghana Medical Journal 2013;47(1):10-5.

9. Pradhananga RB, Adhikari P, Thapa NM, et al. Overview of nasal masses. Journal of Institute of Medicine 2008;30(3):13-16.

10. Verma R, Lokesh KP, Gupta K, et al. Sinonasal amelanotic malignant melanoma- a diagnostic dilemma. Egyptian Journal of Ear, Nose, Throat and Allied Sciences 2015;16(3):275-8.

11. Kung B, Deschenes GR, Keane W, et al. Paranasal sinus melanoma masquerading as chronic sinusitis and nasal polyposis. Ear, Nose and Throat Journal 2007;86(9):561-4.

12. Boghani Z, Hussain Q, Kanumuri VV, et al. Juvenile nasopharyngeal angiofibroma: a systematic review and comparison of endoscopic, endoscopic-assisted and open resection in 1047 cases. Laryngoscope 2013;123(4):85969.

13. Panda NK, Gupta G, Sharma S, et al. Nasopharyngeal Angiofibroma-changing trends in the management. Indian J Otolaryngol Head Neck Surg 2012;64(3):233-9.

14. Iwata N, Hattori K, Nakagawa T, et al. Hemangioma of the nasal cavity: a clinicopathologic study. Auris Nasus Larynx 2002;29(4):335-9.

15. Archontaki M, Stamou AK, Hajiioannou JK, et al. Cavernous haemangioma of the left nasal cavity. Acta Otorhinolaryngologica Italica 2008;28(6):309-11. 
16. Barnes L. Schneiderian Papillomas and Non-salivary Glandular Neoplasms of the Head and Neck. Mod Pathol 2002;15(3):279-7.

17. Wassef SN, Batra PS, Barnett S. Skull base inverted papilloma: a comprehensive review. ISRN Surgery, 2012;2012:175903. doi:10.5402/2012/175903.

18. Fasunla AJ, Lasisi AO. Sinonasal malignancies: a 10 year review in a tertiary health institution. Journal of the National Medical Association 2007;99(12):1407-10.

19. Aozasa K, Takakuwa T, Hongyo T, et al. Nasal NK/T cell lymphoma: epidemiology and pathogenesis. Int J Hematol 2008;87(2):110-7.

20. Howard J, Lund V. Granulomatous conditions of nose. In: Gleeson M. edr. Scott- Brown's Otolaryngology, Head and neck surgery. Vol 2. 7th edn. London: Hodder Arnold 2008:1645-59.

21. Metgud RS, Doshi JJ, Gaurkhede S, et al. Extranodal NK/Tcell lymphoma, nasal type (angiocentric $\mathrm{T}$-cell lymphoma) a review about the terminology. J Oral Maxillofac Pathol 2011;15(1):96-100.

22. Kwong YL. The diagnosis and management of extranodal NK/T cell lymphoma, nasal type and aggressive NK- cell leukemia. J Clin Exp Haematopathol 2011;51(1):21-8.

23. Tural D, Yildiz O, Selcukbiricik F, et al. Olfactory Neuroblastomas: an experience of 24 years. ISRN Oncology Article ID 451086, 2011;2011. P. 7. doi: 10. 5402/2011/ 451086.
24. Menon S, Pai P, Sengar M, et al. Sinonasal malignancies with neuroendocrine differentiation: case series and review of literature. Indian Journal of Pathology and Microbiology 2010;53(1):28-34.

25. Akhtar S, Ikram M, Azam I, et al. Factors associated with recurrent nasal polyps: a tertiary care experience. J Pak Med Assoc 2010;60(2):102-4.

26. Wynn R, Har-El G. Recurrence rates after endoscopic sinus surgery for massive sinus polyposis. Laryngoscope 2004;114(5):811-3.

27. Saha SN, Ghosh A, Sen S, et al. Inverted papilloma: a clinicopathological dilemma with special reference to recurrence and malignant transformation. Indian J Otolaryngol Head Neck Surg 2010;62(4):354-9.

28. Barnes L. Schneiderian papillomas and non-salivary glandular neoplasms of the head and neck. Mod Pathol 2002;15(3):279-97.

29. Won SH, Chun SH, Kim B, et al. Treatment outcome of maxillary sinus cancer. Rare Tumors 2009;1(2):e36.

30. Soon BK, Lim XR, Ng DH, et al. Sinonasal natural killer/Tcell lymphoma presenting as pyrexia of unknown origin with nasal symptoms. Singapore Med J 2014;55(7): e109e111.

31. Chalastras T, Elefteriadou A, GioTakis J, et al. NonHodgkin's lymphoma of nasal cavity and paranasal sinuses. A clinicopathological and immunohistochemical study. Acta Otorhinolaryngol Ital 2007;27(1):6-9. 